\title{
ANALISIS PEMILIHAN SUPPLIER DAN PENENTUAN JUMLAH PEMBELIAN BAHAN BAKU DENGAN MENGGUNAKAN METODE ANALYTIC NETWORK PROCESS (ANP)
}

\author{
Citra Indah Asmarawati ${ }^{1 *}$ dan Sadiq Ardo Wibowo ${ }^{2}$
}

\author{
${ }^{1}$ Program Studi Teknik Industri, Fakultas Teknik dan Komputer, Universitas Putera Batam \\ ${ }^{2}$ Program Studi Teknik Industri, Fakultas Teknologi Industri, Institute Teknologi Batam \\ ${ }^{1}$ Jl. R. Soeprapto, Muka Kuning, Kibing, Kec. Batu Aji, Kota Batam, Kepulauan Riau, 29434 \\ ${ }^{2}$ The Vitka City Complex Jl. Gajah Mada, Tiban Sekupang, Batam, Kepulauan Riau, 29424 \\ "email: citraasmarawati93@gmail.com
}

\begin{abstract}
PT Guna Kemas Indah in determining the supplier of raw materials, but the existing criteria are not sufficient to meet the expected criteria. By using Analytical networking process (ANP) and goal programming in determining quality. In addition, it can also be seen how much raw material purchases are based on the selected supplier. Selection of suppliers is based on several criteria using vendor performance indicators, which are arranged based on sub-criteria. Where the existing subcriteria can influence each criterion. Based on the weight calculation for the criteria are success-quality (0.3868), cost (0.3668), delivery (0.1256), flexibility (0.0619), responsiveness (0.0586) so that 3 supplier candidates will be obtained.
\end{abstract}

Keywords: Supplier, ANP, Goal Programming

\section{Pendahuluan}

Pada supply chain terdapat aktivitas-aktivitas yang dilakukan untuk mendapatkan bahan baku hingga produk jadi ke tangan konsumen. Aktivitas-aktivitas ini melingkupi transaksi pembelian dan aktivitas penting yang berkaitan antara pemasok (supplier) dan distributor (Darmawan \& Setiawan, 2013).

Aktivitas pembelian memiliki tujuan untuk memperoleh bahan baku yang diperoleh dari supplier sebagai sumber penyuplai bahan baku yang dibutuhkan oleh suatu industri (Akbar et al., 2016). Bahan baku yang digunakan oleh suatu industri biasanya cukup bervariasi, satu jenis bahan baku bisa disuplai beberapa supplier. Hal ini kan membuat seringnya terjadi permsalahan terkait penentuan supplier (Nurmalasari \& Pratama, 2018).

PT Guna kemas Indah merupakan salah satu industri pengolahan plastik yang telah lama berdiri Indonesia. Menggunakan mesin-mesin berteknologi tinggi untuk menghasilkan bermacam-macam produk salah satunya adalah cup air minum kemasan. Hanya terdapat beberapa kriteria pemilihan supplier yang selama ini telah digunakan oleh PT Guna Kemas Indah dalam menentukan supplier bahan bakunya. Tapi kriteria yang ada dianggap belum cukup untuk mengakomodasi keseluruhan kriteria yang diharapkan oleh PT Guna Kemas Indonesia.
Evaluasi pemilihan supplier sebenarnya telah dilakukan tetapi hasilnya tidak secara nyata diterapkan. Selain itu dalam penentuan jumlah pembelian bahan baku masih dilakukan secara random dan bias. Hal ini memunculkan berbagai macam permasalahan seperti kualitas dan kuantitas yang tidak sesuai standar dan delay pengiriman bahan baku. Untuk menanggulangi permasalahn ini perlu adanya perbaikan terkait pemilihan dan penentuan supplier. Karena jika dibiarkan terjadi terus menerus perusahan dapat mengalami kerugian yang sangat besar.

Terdapat berbagai macam model pemilihan supplier yang dapat digunakan, salah satunya adalah metode Analytical Networking Process (ANP) dan penentuan jumlah pembelian bahan baku menggunakan metode Goal Programming. Metode Analytical Network Process (ANP), dengan metode ini akan diperoleh bobot dari masing-masing kriteria dan nilai performane supplier untuk kriteria-kriteria yang akan diterapkan (Lee et al., 2012). Kriteria dalam memilih supplier sangat bervariasi dan banyak, tetapi semua ini tidak bisa langsung diterapkan keperusahaan (Blome et al., 2014). Dengan menggunakan metode Vendor Performnce Indicator (VPI ) dimana indicator yang digunakan terdiri dari Quality, Cost, Delivery, Flexibility, dan Reasponsiveness (Andika et al., 2013). 
Goal Programming merupakan salah satu penyelesaian yang dapat digunakan dengan mempertimbangkan berbagai macam factor baik factor kualitatif maupun kuantitatif (Papathanasiou \& Ploskas, 2018). Dengan menggunakan Goal Programming dapat membantu perusahaan dalam menentukan bobot dan prioritas pada saat memberikan nilai performa supplier berdasarkan ktiteria yang ada (Jones \& Tamiz, 2016).

\section{Landasan Teori}

\subsection{Pemilihan Supplier}

Pemilihan supplier merupakan langkah yang sangat penting dalam sebuah manufaktur. Hal ini dikarenakan untuk memperoleh pemasok (supplier) yang terbaik sesuai dengan persyaratan yang diinginkan oleh perusahaan(N. Wulandari, 2014). Terdapat banyak metode ataupun model yang bisa digunakan dalam memilih supplier (Handayani \& Darmianti, 2017). Hal ini didukung oleh beberapa persyaratan yang bisa digunakan sebagai pertimbangan ketika ingin melakukan pemilihan supplier. Proses pemilihan supplier dapat menjadi sebuah kegiatan yang kompleks dan menguras energi ataupun waktu (R. Wulandari, 2017). Terdapat beberapa kriteria yang umum digunakan oleh perusahaan dalam memilih supplier seperti biaya, konsistensi baik dalam kualitas maupun ketepatan waktu, hubungan baik dengan perusahaan, hingga tingkat pelayanannya (Nurmalasari \& Pratama, 2018).

\subsection{Analytical Networking Process}

Pengambilan keputusan merupakan tindakan yang pernah dilakukan oleh manusia dan kegiatan ini sering sekali berdampak langsung terhadap kehidupan. Perlu adanya kehati-hatian dalam pengambilan keputusan apalagi jika hal ini berkaitan dengan pengambilan keputusan yang berkaitan dengan hal-hal penting(Agung, 2016). Salah satu alternatifmetode yang bisa digunakan dalam mengambil keputusan adalah Analytical Networking Process (ANP)(Kadoić et al., 2017).

Analytical Networking Process (ANP) pada prinsipnya menggunakan skala prioritas yang diterapkan juga pada metode AHP (Lee et al., 2012). ANP mampu menunjukan pengaruh antar kriteria dan terdapat interaksi dan umpan balik dari elemen-elemen dalam cluster dan antar cluster(Görener, 2012). Dalam ANP terdiri dari beberapa tahapan(Yücenur et al., 2011). Diawali dengan membuat konstruksi model dari permasalahan yang ada. Kemudian dilakukan perbandingan berpasangan menggunakan skla ANP . Langkah selanjutnya mentukan ratio konsistesi yang akan menunjukan apakah konsistesnsi nilai yang diberikan oleh expert.
Setelah itu menyusun supermatriks yang merupakan satu set dimana terdapat sub matriks.

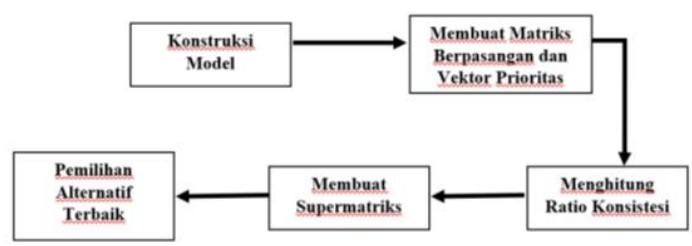

Gambar 1. Langkah-langkah dalam ANP

\subsection{Linier Goal Programming}

Salah satu metode yang merupakan pengembangan linier programming yang memiliki sejumlah fungsi yang ingin dipenuhi, seperti contoh, terdapat suatu perusahaan yang mempunyai intensi untuk memaksimalkan keuntungan dan meminimasi pengeluaran.(Pasic et al., 2012). Tetapi pada linier programming hanya memiliki satu fungsi tujuan atau satu model untuk mengakomodir dan menyelesaikan suatu riset operasi(Arunraj \& Maiti, 2010). Definisi dari riset operasi adalah suatu model matetmatis yang diberfungsi untuk memutustkan solusi terbaik (optimal) dalam suatu permasalahan dimana terdapat keterbatasan sumber daya, hal ini menyebabkan riset operasi sering disebut sebagai salah satu metode optimasi(Prasetyo \& Sutopo, 2018). Linier goal programming ini memiliki beberapa elemen-elemen dan persyaratan yang harus dipenuhi seperti yang terdapat pada linier programming(Sukanteri et al., 2013).

\section{Metode Penelitian}

Objek pada penelitian ini yaitu bahan dasar atau bahan baku bijih plastik pada PT GKI (Guna Kemas Indah), dan melakukan wawancara seta tanya jawab secara langsung kepada pihak yang berkompeten terhadap permasalahan atau pengambil keputusan terhadap bahan baku yang dibeli perusahaan seperti manajer produksi, logistik, PPIC serta QC (quality control).

Dalam tahap pengolahan data, pembobotan kriteria supplier bahan baku bijih plastik dihitung berdasarkan data primer yang didapat dari kuisioner dan diolah dengan metode ANP dengan bantuan software Super Decision, dan alokasi pembelian bahan baku menggunakan metode Goal Programming dengan bantuan software Lindo. Objek pada penelitian ini yaitu bahan dasar atau bahan baku bijih plastik pada PT GKI (Guna Kemas Indah), dan melakukan wawancara serta tanya jawab secara langsung kepada pihak yang berkompeten terhadap permasalahan atau pengambil keputusan terhadap bahan baku yang dibeli perusahaan seperti manajer produksi, logistik, PPIC serta QC (quality control). 


\section{Pembahahasan}

\subsection{Penentuan Kriteria}

Proses penentuan ke semua kriteria tersebut dilakukan dengan mencari literatur dari penelitianpenelitian terdahulu untuk dijadikan pedoman dalam penentuan kriteria dan mengambil informasi atau wawancara pihak expertise tentang kriteria yang dapat digunakan dan dianggap penting di perusahaan. Tahap selanjutnya menggunakan kuisioner untuk menentukan kriteria kriteria dan subkriteria yang krusial untuk perusahaan melalui meletakan kriteria-subkriteria pada kolom yang telah ada. Kuisioner diisikan oleh 4 orang dari top management yaitu manajer produksi, logistik, PPIC serta QC (quality control). Expert yang ditentukan berdasar keterkaitannya pada saat pembelian bahan baku. Berdesarkan kuisioner yang telah diberikan diperoleh hasil yang terlihat pada Tabel 1 berikut ini:

Tabel 1 Kriteria dan Subkriteria

\begin{tabular}{ccl}
\hline No & Kriteria & \multicolumn{1}{c}{ Subkriteria } \\
\hline \multirow{2}{*}{1} & Quality & Kualitas Bahan Baku \\
& (Kualitas) & Kelengkapan Sertifikat \\
& & Harga Bahan Baku \\
& Cost (Harga) & Periode Pembayaran \\
& & Tagihan \\
& & Ketepatan Jumlah \\
& & Bahan Baku Yang \\
3 & Delivery & Dikirim \\
& (Pengiriman) & Waktu Pengiriman \\
& & Bahan Baku \\
& & Perubahan Volume \\
4 & Flexibility & Bahan Baku \\
& (Fleksibilitas) & Perubahan Waktu \\
& & Pengiriman \\
& & Respon Perubahan \\
& & Jumlah Permintaan \\
5 & Responsiveness & Respon Perubahan \\
& (Respon) & Jadwal Pengiriman \\
& & Respon Dalam \\
& & Problem Kualitas \\
\hline
\end{tabular}

\subsection{Tahapan ANP (Analytical Networking Process)}

\subsubsection{Mengkonstruksikan Model}

Untuk menyusun ANP, dibutuhkan nilai bobot untuk masing-masing kriteria dan subkriterianya. Perlunya indentifikasi untuk mengetahui hubungan yang saling mempengaruhi antar subkriterianya, dengan cara menyebarkan kuisoner 2 pada responden yang mengisi kuisioner 1 .
Tabel 2 Subkriteria Yang Saling Mempengaruhi

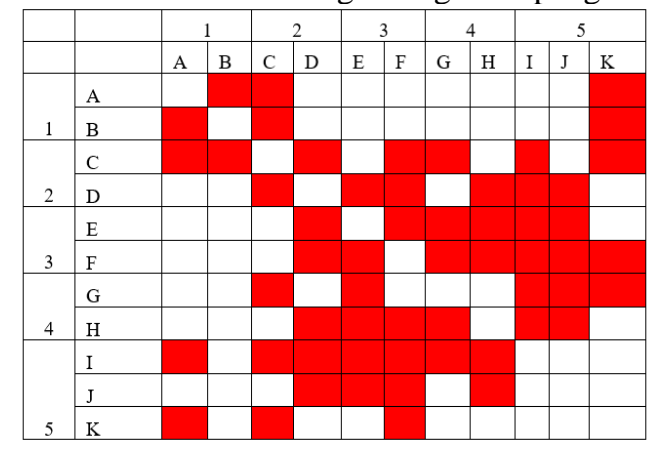

Setelah diperoleh kriteria dan subkriteria yang dipergunakan untuk menilai performa supplier, serta hubungan pengaruhnya, maka selanjutnya dibuat model ANP pada software Super Decision. Berikut ini adalah konstruksi model yang dibuat berdasarkan hasil kuisioner kedua:

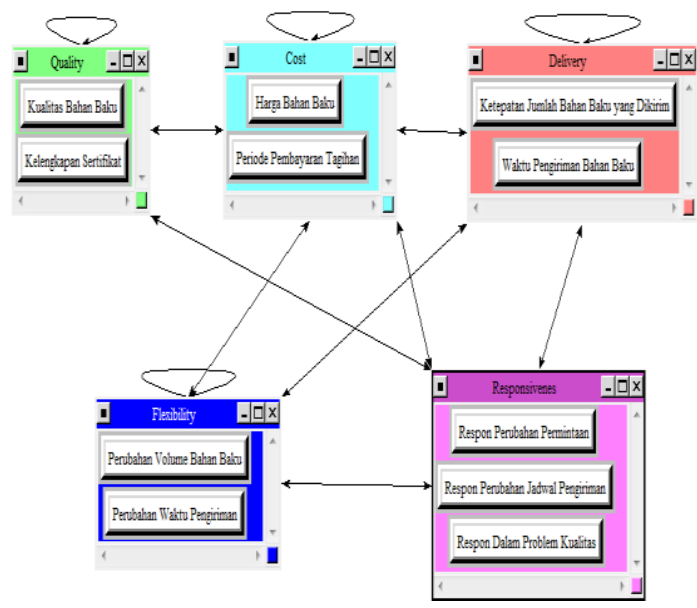

Gambar 2. Model jaringan ANP Penilaian Performa Supplier

\subsubsection{Membuat Matriks Perbandingan Berpasangan}

Matriks perbandingan berpasangan didapatkan dengan menyebarkan kuisioner ketiga, kuisioner ini sama dengan responden pada kuisioner sebelumnya. Menentukan nilai rata-rata (geometric mean) dari penialain yang diberikan oleh responden, agar nilai dapat dimasukan kedalam model super decision. Tidak semua nilai bisa dimasukan kedalam model super decision, terdapat satu nilai saja yang digunakan.

Tabel 3. Rata-rata Penilaian Perbandingan Berpasangan Kriteria

\begin{tabular}{|l|r|r|r|r|r|}
\hline $\begin{array}{l}\text { Performa } \\
\text { Supplier }\end{array}$ & Cost & Delivery & Flexibility & Quality & Responsivenes \\
\hline Cost & 1.00 & 3.482 & 3.708 & 2.943 & 5.544 \\
\hline Delivery & & 1.00 & 2.590 & 3.956 & 5.544 \\
\hline Flexibility & & & 1.00 & 3.948 & 3.344 \\
\hline Quality & & & & 1.00 & 7.297 \\
\hline Responsivenes & & & & & 1.00 \\
\hline
\end{tabular}


Nilai yang diperkenankan untuk dinput ke software super decision, adalah nilai yang berwarna biru saja. Nilai yang berwarna biru menunjukan bahwa matriks perbandingan yang ada kebalikan (resiprokal). Maknanya, apabila elemen $\mathrm{j}$ memiliki nilai diatas pada saat dibandingkan dengan elemen $\mathrm{k}$, maka $\mathrm{k}$ akan mempunyai nilai kenalikan pada saat dibandingkan dengan nilai j. Nilai yang diperoleh merupakan nilai pecahan hasil rata-rata geometric. Untuk memudahkan pada saat input data sebaiknya software yang dipakai adalah tipe "matriks".

\subsubsection{Menghitung Rasio Konsistensi}

Setelah menghitung consistency ratio untuk melakukan perbandingan kriteria yang ada diperoleh nilai consistency ratio lebih kecil dari 0,1 yaitu sebesar dari 0,07534. Nilai consistency ratio yang diperoleh menunjukan bahwa jawaban yang diberikan oleh responden adalah konsisten, terdapat kepastian dan kepercayaan atas jawaban yang diberikan oleh responden terkait nilai perbandingan berpasangan.

\begin{tabular}{|c|c|c|}
\hline Nement - - & 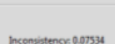 & ment - \\
\hline Cost & & 0.27339 \\
\hline Delivery & & 0.14433 \\
\hline Flexibili & & 0.08576 \\
\hline Quality & & 0.45874 \\
\hline Responsiv & & 0.03778 \\
\hline
\end{tabular}

Gambar 3. Pengecekan Konsistensi

\subsubsection{Membentuk Super Matriks}

Setelah seluruh data nilai perbandingan dimasukkan, maka diperoleh unweighted matrix, weighted matrix, dan limit matrix. Kemudian agar dapat mengetahui bobot terbesar atau yang menjadi prioritas pada saat melakukan pengukuran supplier, dengan cara melihat nilai yang hampir mencapai 1.

Tabel 5. Bobot Kriteria Dan sub Kriteria

\begin{tabular}{|c|c|c|c|c|c|}
\hline \multirow{2}{*}{$\mathrm{N}_{0}$} & \multirow{2}{*}{ Kriteria } & \multirow{2}{*}{$\begin{array}{c}\text { Bobot } \\
\text { Kriteria }\end{array}$} & \multirow{2}{*}{ Subkriteria } & \multicolumn{2}{|c|}{$\begin{array}{c}\text { Bobot } \\
\text { Subkriteria }\end{array}$} \\
\hline & & & & $\begin{array}{l}\text { Pada } \\
\text { Cluster }\end{array}$ & Global \\
\hline \multirow{2}{*}{1} & \multirow{2}{*}{ Harga } & \multirow{2}{*}{0.366865} & Harga Bahan Baku & 0.7117 & 0.2611 \\
\hline & & & Periode Pembayaran Tagihan & 0.2883 & 0.1058 \\
\hline \multirow{2}{*}{2} & \multirow{2}{*}{ Pengiriman } & \multirow{2}{*}{0.125699} & Ketepatan Jumlah Bahan Baku yang Dikirim & 0.4753 & 0.0597 \\
\hline & & & Waktu Pengiriman Bahan Baku & 0.5248 & 0.0660 \\
\hline \multirow{2}{*}{3} & \multirow{2}{*}{ Fleksibilitas } & \multirow{2}{*}{0.061977} & Perubahan Volume Bahan Baku & 0.4952 & 0.0307 \\
\hline & & & Perubahan Waktu Pengiriman & 0.5048 & 0.0313 \\
\hline \multirow{2}{*}{4} & \multirow{2}{*}{ Kualitas } & \multirow{2}{*}{0.386838} & Kelengkapan Sertifikat & 0.5378 & 0.2080 \\
\hline & & & Kualitas Bahan Baku & 0.4622 & 0.1788 \\
\hline \multirow{3}{*}{5} & \multirow{3}{*}{ Respon } & \multirow{3}{*}{0.05862} & Respon Dalam Problem Kualitas & 0.5169 & 0.0303 \\
\hline & & & Respon Perubahan Jadwal Pengiriman & 0.1636 & 0.0096 \\
\hline & & & Respon Perubahan Permintaan & 0.3195 & 0.0187 \\
\hline
\end{tabular}

Untuk memilih supplier terbaik yang dijadikan sebagai pemasok bahan baku, digunakan metode rating. Hal ini dikarenakan terdapat 5 supplier yang ingin dicari nilainya berdasarkan subkriteria yang sudah dijelaskan, sehingga akan membingungkan responden jika perbandingan yang dilakukan adalah perbandingan berpasangan. Setiap supplier memiliki kemungkinan untuk dipilih sebagai pemasok. Alokasi pembelian bahan baku menggunakan performa supplier untuk setiap kriteria sebagai dasarnya, sehingga tidak perlu ditentukan supplier terbaik secara keseluruhan kriteria karena data yang digunakan dalam perhitungan alokasi adalah data performa supplier pada setiap kriteria.

Tabel 6. Nilai Supllier Pada Setiap Kriteria

\begin{tabular}{|c|l|c|c|c|c|c|}
\hline \multirow{2}{*}{$\begin{array}{c}\text { Bahan } \\
\text { Baku }\end{array}$} & \multirow{2}{*}{ Supplier } & \multicolumn{5}{|c|}{ Kriteria } \\
\cline { 3 - 7 } & & Kualitas & Harga & Pengiriman & Fleksibilitas & Respon \\
\hline \multicolumn{2}{|c|}{ Bobot } & 0.3868 & 0.3668 & 0.1256 & 0.0619 & 0.0586 \\
\hline \multirow{2}{*}{$\begin{array}{c}\text { Poly } \\
\text { Propylene }\end{array}$} & PT. 1A & 0.3384 & 0.3825 & 0.1081 & 0.0528 & 0.0763 \\
\cline { 2 - 7 } & PT. 1B & 0.2006 & 0.3008 & 0.1081 & 0.0252 & 0.0456 \\
\cline { 2 - 7 } & PT. 1C & 0.3659 & 0.3679 & 0.1280 & 0.0329 & 0.0499 \\
\cline { 2 - 7 } & PT. 1D & 0.2803 & 0.3008 & 0.0603 & 0.0426 & 0.0481 \\
\cline { 2 - 7 } & PT. 1E & 0.4103 & 0.3819 & 0.1001 & 0.0389 & 0.0499 \\
\hline \multirow{4}{*}{$\begin{array}{c}\text { Poly } \\
\text { Ethylene }\end{array}$} & PT. 2A & 0.3306 & 0.3008 & 0.1081 & 0.0548 & 0.0937 \\
\cline { 2 - 7 } & PT. 2B & 0.4162 & 0.3825 & 0.0484 & 0.0424 & 0.0541 \\
\cline { 2 - 7 } & PT. 2C & 0.3287 & 0.2060 & 0.0847 & 0.0631 & 0.0402 \\
\cline { 2 - 7 } & PT. 2D & 0.4655 & 0.2230 & 0.1325 & 0.0354 & 0.0646 \\
\cline { 2 - 7 } & PT. 2E & 0.3443 & 0.2869 & 0.1478 & 0.0294 & 0.0438 \\
\hline $\begin{array}{c}\text { Chesa } \\
\text { Nucleant }\end{array}$ & PT. 3A & 0.4900 & 0.3965 & 0.1524 & 0.0308 & 0.0616 \\
\cline { 2 - 7 } & PT 3B & 0.4369 & 0.2872 & 0.1081 & 0.0447 & 0.0592 \\
\cline { 2 - 6 } & PT. 3C & 0.4103 & 0.4496 & 0.0735 & 0.0403 & 0.0405 \\
\hline
\end{tabular}

\subsection{Alokasi Pembelian Bahan Baku}

\subsubsection{Data Kendala Pembelian Bahan Baku}

Pada pembelian bahan baku, biasanya terdapat kendala berupa persyaratan pembelian baik yang ditetapkan oleh perusahaan maupun oleh supplier. Berdasarkan hasil wawancara dengan manager purchasing, kendala yang ada pada perusahaan dalam pembelian maksimum dan minimum dari supplier.

\subsubsection{Formulasi Model Pembelian Bahan Baku}

Penentuan alokasi pembelian bahan baku ini dilakukan dengan menyelesaikan model goal programming tipe weighted method. Karena perusahaan tidak menetapkan target level yang harus dicapai oleh setiap kriteria, maka target level tersebut harus dicari terlebih dahulu dengan penyelesaian persamaan linier programming. Selanjutnya, data-data batasan pembelian dan kendala tujuan dari setiap kriteria diformulasikan dan diselesaikan dengan goal programming.

\subsubsection{Pemilihan Subkriteria Terbaik}


Tabel 7. Alokasi Pembelian Bahan Baku

Bahan
Baku $\quad \begin{gathered}\text { Alokasi } \\ \text { Pembelian }\end{gathered}$

\begin{tabular}{ccc}
\hline & $1 \mathrm{~A}$ & - \\
Poly & $1 \mathrm{~B}$ & - \\
Propylene & $1 \mathrm{C}$ & - \\
& $1 \mathrm{D}$ & - \\
& $1 \mathrm{E}$ & $200000 \mathrm{~kg}$ \\
& $2 \mathrm{~A}$ & - \\
Poly & 2B & $25000 \mathrm{~kg}$ \\
Ethylene & 2C & - \\
& $2 \mathrm{D}$ & - \\
& $2 \mathrm{E}$ & - \\
Chesa & $3 \mathrm{~A}$ & $2000 \mathrm{~kg}$ \\
Nucleant & 3B & - \\
& $3 \mathrm{C}$ & - \\
\hline
\end{tabular}

\subsection{Analisis Data}

Dapat dilihat pada hasil goal programming bahwa alokasi supplier untuk setiap bahan baku juga memiliki sifat yang konsisten dengan prioritas ini. Dapat dilihat bahwa jika kendala-kendala pada perusahaan yang ada tidaklah kompleks, maka hasil pembelian bahan baku yang diberikan oleh goal programming akan konsisten dengan hasil urutan prioritas pada nilai supplier yang dapat diperoleh dari tahapan ANP.

Tabel 8. Nilai Total Supplier

\begin{tabular}{ccc}
\hline Bahan Baku & Supplier & Nilai Supplier \\
\hline & PT. 1A & 0.958100 \\
Poly & PT. 1B & 0.680300 \\
Propylene & PT. 1C & 0.944600 \\
& PT. 1D & 0.732100 \\
& PT. 1E & 0.981100 \\
& PT. 2A & 0.888000 \\
Poly & PT. 2B & 0.943600 \\
Ethylene & PT. 2C & 0.722718 \\
& PT. 2D & 0.921000 \\
& PT. 2E & 0.852200 \\
& PT. 3A & 1.131300
\end{tabular}

\begin{tabular}{ccc}
$\begin{array}{c}\text { Chesa } \\
\text { Nucleant }\end{array}$ & PT 3B & 0.936100 \\
& PT. 3C & 1.014200 \\
\hline
\end{tabular}

Langkah selanjutnya yang dapat dilakukan perusahaan adalah mengevaluasi performa supplier ini secara berkala karena memungkinkan adanya perubahan alokasi pembelian bahan baku, menjaga hubungan dengan supplier, dan terus mencari calon supplier berkompeten lainnya sehingga supplier-supplier akan lebih giat bersaing karena pasar semakin kompetitif.

\section{Kesimpulan}

Pada penelitian ini didapatkan kriteria dan subkriteria yang akan diterapkan pada PT Guna Kemas Indah dalam penentuan supplier. Kriteria quality (kualitas bahan baku dan kelengkapan sertifikat), cost (harga bahan baku dan periode pembayaran tagihan), delivery (ketepatan jumlah bahan baku yang dikirim dan waktu pengiriman bahan baku), flexibility (perubahan volume bahan baku dan perubahan waktu pengiriman), dan responsiveness (respon jumlah perubahan jumlah permintaan, respon perubahan jadwal pengiriman dan respon dalam problem kualitas).

Berdasarkan metode ANP dan Goal Programming supplier yang tepilih adalah 1E, 2B dan 3A. sedangkan untuk jumlah pembelian bahan baku supplier 1E sebanyak $200000 \mathrm{~kg}$, supplier 2B $25000 \mathrm{~kg}$ dan supplier 3A sebesar $2000 \mathrm{~kg}$. Dapat dilihat pada hasil goal programming bahwa alokasi supplier untuk setiap bahan baku juga memiliki sifat yang konsisten dengan prioritas ini. Dapat dilihat bahwa jika kendala-kendala pada perusahaan yang ada tidaklah kompleks, maka hasil pembelian bahan baku yang diberikan oleh goal programming akan konsisten dengan hasil urutan prioritas pada nilai supplier yang dapat diperoleh dari tahapan ANP.

Langkah selanjutnya yang dapat dilakukan perusahaan adalah mengevaluasi performa supplier ini secara berkala karena memungkinkan adanya perubahan alokasi pembelian bahan baku, menjaga hubungan dengan supplier, dan terus mencari calon supplier berkompeten lainnya sehingga supplier-supplier akan lebih giat bersaing karena pasar semakin kompetitif.

\section{Daftar Referensi}

Agung, I. G. N. (2016). Analisis Statistik Sederhana Untuk Pengambilan Keputusan. Populasi. https://doi.org/10.22146/jp.12342

Akbar, P. G., Henmaidi, H., \& Amrina, E. (2016). Usulan Indikator Evaluasi Pemasok dalam Penetapan Bidder List: Studi Kasus 
Pengadaan Jasa PT. Semen Padang. Jurnal Optimasi Sistem Industri. https://doi.org/10.25077/josi.v14.n1.p3954.2015

Andika, D., Anggraeni, S. K., \& Sirajuddin. (2013). Usulan Pemilihan Supplier Bahan Baku Tetap Menggunakan Vendor Performance Indicator dan Analytical Hierarchy Process ( AHP ). Jurnal Teknik Industri. https://doi.org/10.1073/pnas.0712031105

Arunraj, N. S., \& Maiti, J. (2010). Risk-based maintenance policy selection using AHP and goal programming. Safety Science. https://doi.org/10.1016/j.ssci.2009.09.005

Blome, C., Hollos, D., \& Paulraj, A. (2014). Green procurement and green supplier development: Antecedents and effects on supplier performance. International Journal of Production Research. https://doi.org/10.1080/00207543.2013.825 748

Darmawan, H., \& Setiawan, H. (2013). Pemilihan Pemasok Bahan Baku Produksi Menggunakan Metode Data Envelopment Analysis. Jurnal Teknik Industri.

Görener, a. (2012). Comparing AHP and ANP: An Application of Strategic Decisions Making in a Manufacturing Company. International Journal of Business and Social Science.

handayani, rani irma, \& darmianti, yuni. (2017). Sistem Pendukung Keputusan Pemilihan Supplier Dengan Metode Analytical Hierarchy Process Pada PT. Cipta Nuansa Prima Tangerang. Jurnal Techno Nusa Mandiri.

Jones, D., \& Tamiz, M. (2016). A review of goal programming. International Series in Operations Research and Management Science. https://doi.org/10.1007/978-14939-3094-4_21

Kadoić, N., Ređep, N. B., \& Divjak, B. (2017). Decision making with the analytic network process. Proceedings of the 14th International Symposium on Operational Research, SOR 2017. https://doi.org/10.1007/0-387-33987-6

Lee, H., Kim, M. S., \& Park, Y. (2012). An analytic network process approach to operationalization of five forces model.
Applied Mathematical Modelling. https://doi.org/10.1016/j.apm.2011.09.012

Nurmalasari, \& Pratama, A. A. (2018). Sistem Pendukung Keputusan Pemilihan Supplier Menggunakan Metode AHP Pada PT Transcoal Pacific Jakarta. Jurnal Teknik Komputer AMIK BSI (JTK). https://doi.org/10.31294/jtk.v4i2.3509

Papathanasiou, J., \& Ploskas, N. (2018). Goal programming. In Springer Optimization and Its Applications. https://doi.org/10.1007/978-3-319-91648 4_6

Pasic, M., Catovic, A., Bijelonja, I., \& Bahtanovic, A. (2012). Goal programming nutrition optimization model. 23rd DAAAM International Symposium on Intelligent Manufacturing and Automation 2012.

Prasetyo, H., \& Sutopo, W. (2018). Industri 4.0: Telaah Klasifikasi Aspek Dan Arah Perkembangan Riset.J@ti Undip : Jurnal Teknik Industri. https://doi.org/10.14710/jati.13.1.17-26

Sukanteri, N. P., Narka Tenaya, M., \& Budiasa, I. W. (2013). Pemodelan Sistem Pertanian Terintegrasi Pendekatan: Programasi Linier Optimization Analysis of Integrated Farming Systems : Linear Programming Approach. Jurnal Manajemen Agribisnis.

Wulandari, N. (2014). Perancangan Sistem Pendukung Keputusan Pemilihan Supplier di PT . Alfindo dengan Metode Analytical Hierarchy Process (AHP). Jurnal Sistem Informasi Vol-1. https://doi.org/24067768

Wulandari, R. (2017). Pemilihan Supplier Bahan Baku Partikel Dengan Metode AHP Dan Promethee. Jurnal Teknik Industri. https://doi.org/10.22219/jtiumm.vol16.no1. 22-30

Yücenur, G. N., Vayvay, Ö., \& Demirel, N. Ç. (2011). Supplier selection problem in global supply chains by AHP and ANP approaches under fuzzy environment. International Journal of Advanced Manufacturing Technology. https://doi.org/10.1007/s00170-011-3220-y 